Measurements \& Characterization • National Center for Photovoltaics Analytical Microscopy

We combine two complementary areas of analytical microscopyelectron microscopy and proximal-probe techniques—and use a variety of state-of-the-art imaging and analytical tools. We also design and build custom instrumentation and develop novel techniques that provide unique capabilities. In our work, we collaborate with you to solve materials- and device-related R\&D problems. This sheet summarizes the uses and features of four major tools: transmission electron microscopy, scanning electron microscopy, the dual-beam focused-ion-beam workstation, and scanning probe microscopy.

\section{TRANSMISSION ELECTRON MICROSCOPY}

In transmission electron microscopy (TEM), a thin sample, less than $200 \mathrm{~nm}$ thick, is bombarded by a highly focused beam of singleenergy electrons. The beam has enough energy for the electrons to be transmitted through the sample, and the transmitted electron signal is greatly magnified by a series of electromagnetic lenses.

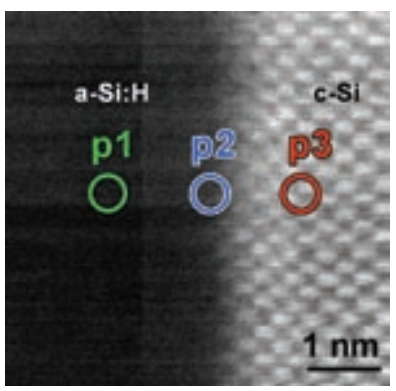

High-resolution Z-contrast image of a c-Si/a-Si interface from a highefficiency Si heterojunction solar cell. The image reveals an atomically abrupt and flat c-Si/a-Si interface.

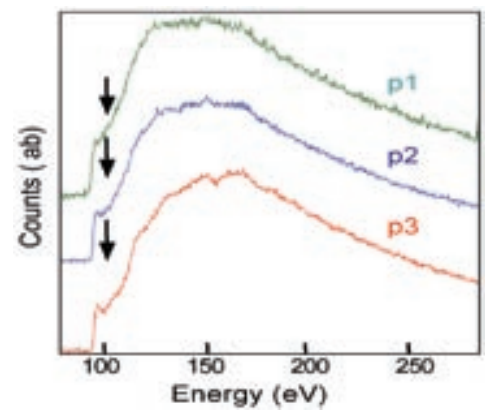

Electron energy-loss spectroscopy at three different positions reveals the changes of electronic property from the $c$-Si to the interface and to the a-Si regions (see peaks indicated by black arrows).
The magnified transmitted signal may be observed in several ways - by electron diffraction, diffraction-contrast imaging, or phase-contrast imaging. Transmission electron diffraction (TED) patterns help to determine the crystallographic structure of the material. Diffraction-contrast images yield information about the chemistry and microstructure of the material and about its defects. Phase-contrast imaging or high-resolution TEM imaging gives information about the microstructure of the material and its defects at an atomic resolution.

With scanning transmission electron microscopy (STEM), the electron beam is raster-scanned across the material, which produces a variety of electron and X-ray signals used for compositional and electronic analysis. The transmitted electrons at high scattering angle can be collected to form high-resolution, chemically sensitive Z-contrast images.

\section{Applications}

- Crystallography. Electron diffraction enables one to determine the crystallographic structure of materials on a fine scale.

- Microstructure. Diffraction-contrast and high-resolution TEM yields information on the composition, microstructure, and atomic structure of materials and defects. High-resolution STEM Z-contrast imaging provides directly interpretable, chemically sensitive images of the structure of materials, defects, and interfaces in samples with atomic resolution.

- Composition. Energy-dispersive X-ray spectroscopy (EDS) and electron energy-loss spectroscopy (EELS) provide quantitative and qualitative compositional analysis of materials to sub$\mathrm{nm}$ spatial resolution for almost any element. STEM EDS and EELS enable elemental mapping to be performed with $\mathrm{nm}$-scale resolution. EELS also provides information on the electronic properties of materials. A Gatan image filter (GIF) enables elemental mapping to be performed by energyfiltered TEM with high spatial resolution.

- Cross-sectional analysis. Investigates the structure, composition, and perfection of multilayer films and interfaces.

\section{Features}

- Field-emission gun STEM. Enables structural, compositional, and electronic

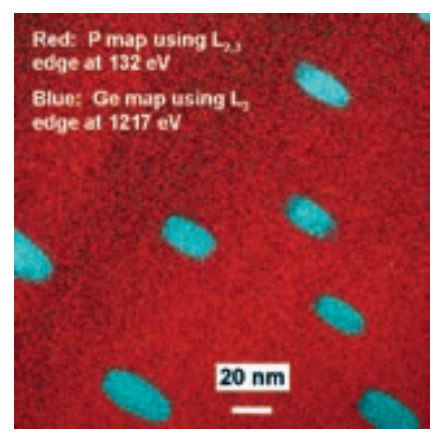

GIF energy-filtered TEM elemental map of Ge nanowires embedded in GalnP matrix.

MAJOR INSTRUMENTATION FOR TRANSMISSION ELECTRON MICROSCOPY

\begin{tabular}{l|l|l|l|l}
\hline System & Analytical Technique & Typical Applications & Lateral Resolution & Special Features \\
\hline Phillips CM30 & $\begin{array}{l}\text { Transmission electron } \\
\text { microscopy }\end{array}$ & $\begin{array}{l}\text { Structural and compositional } \\
\text { analysis and lattice imaging }\end{array}$ & $0.23 \mathrm{~nm}$ & High-resolution, EDS \\
\hline FEI F20 (UT) & $\begin{array}{l}\text { Field-emission scanning } \\
\text { transmission electron } \\
\text { microscopy }\end{array}$ & $\begin{array}{l}\text { Structural, electronic, and } \\
\text { compositional analysis; elemental } \\
\text { mapping; lattice imaging }\end{array}$ & $\begin{array}{l}0.19 \mathrm{~nm} \text { for HRTEM; } \\
0.14 \mathrm{~nm} \text { for Z-contrast } \\
\text { STEM }\end{array}$ & $\begin{array}{l}\text { High-resolution, Z-contrast, EDS, } \\
\text { EELS, Energy filtering, Field- } \\
\text { emission electron source }\end{array}$ \\
\hline FEI NOVA 200 & $\begin{array}{l}\text { Field-emission scanning } \\
\text { electron (SEM) and ion } \\
\text { (SIM) microscopy }\end{array}$ & $\begin{array}{l}\text { Preparation of TEM and SEM } \\
\text { samples. Fabrication of nano- } \\
\text { structures }\end{array}$ & $\begin{array}{l}1.1 \mathrm{~nm} \text { SEM 15 kV for } \\
7 \mathrm{~nm} \text { for SIM }\end{array}$ & $\begin{array}{l}\text { THERMO EDS } \\
\text { FIB etch and deposition } \\
\text { High-resolution SEM }\end{array}$
\end{tabular}


analysis with sub-nm spatial resolution.

- STEM high-angle annular dark-field detector.

Enables high-resolution ( 0.14 nm) STEM Z-contrast microscopy, providing directly interpretable, chemically sensitive atomic resolution images.

- Gatan image filter (GIF). Enables EELS spectroscopy

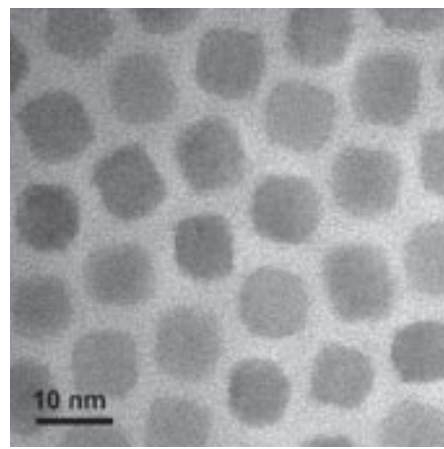

High-resolution TEM image of array of colloidal PbTe nanocrystals. and elemental mapping to be performed for a wide range of elements and energy-filtered electron diffraction and imaging.

- Energy dispersive X-ray spectroscopy (EDS) systems. Enables compositional analysis and elemental mapping with high spatial resolution.

- Low-energy low-temperature ion milling system. Reduces damage during sample preparation.

- Dual-beam focused-ion-beam (FIB) workstation. Enables site-specific preparation of TEM samples.

\section{SCANNING ELECTRON MICROSCOPY}

In scanning electron microscopy (SEM), highly energetic (0.1-40 $\mathrm{keV}$ ) electrons are focused and scanned over the surface being

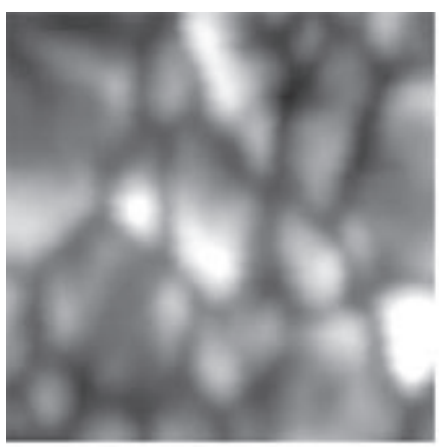

$1.08 \mathrm{eV}$

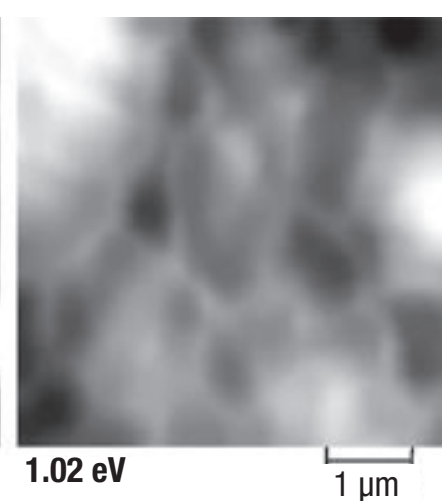

$1 \mu \mathrm{m}$
Maps of photon intensity for different transitions identitied on the emission spectrum of CIGS thin films. Grain boundaries show a distinct electronic behavior. observed, causing multiple interactions: emission of secondary and backscattered electrons, photons, $\mathrm{X}$-rays, excitation of phonons, and diffraction under specific conditions. Because the electron beam is scanned in the X-Y plane, an image for each of these different processes can be obtained when using a suitable detector. Detection of secondary electrons - a standard practice in SEM-provides the topography of the surface being observed with a resolution on the order of 1-2 $\mathrm{nm}$ and magnification from 10x to 500,000x. In addition, we can map information on composition, phase, and other multiple properties (e.g., electrical, optical, thermal) with excellent resolution by adding appropriate detectors. The SEM is perhaps the most versatile instrument in materials science because-beyond being a stand-alone instrument-it represents an integrated platform for a wide variety of characterization techniques.

\section{Applications}

- Topography. Secondary electrons, with energies from 0 to $50 \mathrm{eV}$, provide an image of the surface being observed with very high resolution and depth of field at very high scanning speeds. Best resolution is obtained with in-lens detectors in microscopes with field-emission sources.

- Composition. Backscattered electron emission is sensitive to composition and is used to form compositionally sensitive images. Moreover, using characteristic X-rays, maps of different elements can be obtained with micrometer resolution.

\section{- Electron-beam-induced} current (EBIC).

In the presence of an electrostatic field $(p-n$ junction), electron-hole (e-h) pairs excited by the electron beam can be collected, and the resulting current is amplified with a picoamplifier and used to form an EBIC image. EBIC provides information about the location of

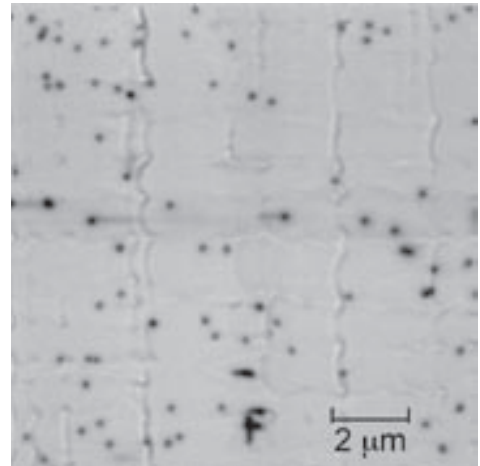

Electron-beam-induced current image of a GaAsP-on-Si solar cell revealing threading dislocations crossing the $p-n$ junction.

\section{MAJOR INSTRUMENTATION FOR SCANNING ELECTRON MICROSCOPY}

\begin{tabular}{|c|c|c|c|c|}
\hline System & Analytical Technique & Typical Applications & $\begin{array}{l}\text { Lateral } \\
\text { Resolution }\end{array}$ & Special Features \\
\hline JEOL 6320F & $\begin{array}{l}\text { Field-emission } \\
\text { scanning electron } \\
\text { microscopy }\end{array}$ & $\begin{array}{l}\text { Micro- and nanoscale } \\
\text { characterization of topography, } \\
\text { composition and phases }\end{array}$ & $\begin{array}{l}1.2 \mathrm{~nm} @ 1.5 \mathrm{kV} \\
2.5 \mathrm{~nm} @ 1 \mathrm{kV}\end{array}$ & $\begin{array}{l}\text { HKL NORDLYS II EBSD } \\
\text { THERMO EDS, EBIC }\end{array}$ \\
\hline JEOL JSM-5800 & $\begin{array}{l}\text { Scanning electron } \\
\text { microscopy }\end{array}$ & $\begin{array}{l}\text { Microstructure, EBIC, } \\
\text { cathodoluminescence }\end{array}$ & $3.5 \mathrm{~nm}$ & $\begin{array}{l}\text { Cathodoluminescence spectrum } \\
\text { imaging, cryostage ( } 15 \text { to } 300 \mathrm{~K} \text { ), } \\
\text { CCD, InGaAs PDA }\end{array}$ \\
\hline $\begin{array}{l}\text { Customized SPM } \\
\text { platform }\end{array}$ & STM, AFM, NSOM & $\begin{array}{l}\text { Nanoscale characterization and } \\
\text { manipulation of nanostructures }\end{array}$ & $<1 \mathrm{~nm}$ & $\begin{array}{l}\text { Scanning tunneling } \\
\text { luminescence, } \\
\text { electroluminescence, lateral } \\
\text { transport measurements, NFCL }\end{array}$ \\
\hline JEOL JXA-8900L & $\begin{array}{l}\text { Electron probe } \\
\text { microanalysis (EPMA) }\end{array}$ & $\begin{array}{l}\text { Quantitative compositional } \\
\text { analysis }\end{array}$ & $100 \mathrm{~nm}$ to $5 \mathrm{~mm}$ & \pm 0.2 at. $\%$ detection limit \\
\hline
\end{tabular}


the junction in a device, shunts, electrical activity of grain boundaries, and diffusion length.

- Cathodoluminescence (CL). CL is the photon emission stimulated by the electron beam. CL can be used to investigate the distribution of recombination centers in semiconductors, including extended defects (dislocations, grain boundaries), stress fields, and compositional fluctuations. At NREL, we have combined spectroscopy and imaging into a single mode: spectrum imaging. Basically, spectrum imaging acquires a spectrum for each pixel on the image at high speed (typically $10 \mathrm{~ms} /$ pixel). This is achieved by synchronizing the scanning of the electron beam with the spectrum acquisition. In our system, CL observations can be performed at temperatures between 15 and $300 \mathrm{~K}$.

- Electron backscattered diffraction (EBSD). EBSD indexes diffraction patterns for each pixel on the image, providing maps of the orientation of crystalline phases, misorientation between grains, texture, grain distribution, deformation, and strain.
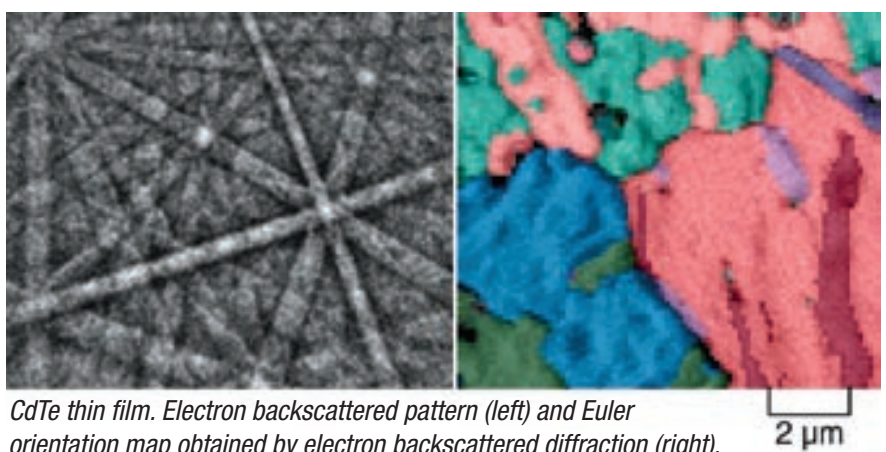

orientation map obtained by electron backscattered diffraction (right).

- Scanning-probe microscopy (SPM) platform. We have developed a very compact SPM integrated with SEM. Combining these two platforms, the following operation modes are available:

- Scanning tunneling luminescence-Based on scanning tunneling microscopy (STM), the photon emission is stimulated by tunneling electrons and can be applied to nanostructures.

- Lateral transport-Based on a combination of STM and SEM, e-h pairs excited by the electron beam at specific locations are detected through the STM tip and the lateral electron diffusion can then be measured.

- Electroluminescence mapping-Based on conductive atomic force microscopy (C-AFM), individually injected current pulses during intermittent contact are used to stimulate electroluminescence when the $p$-n junction is under forward bias.

- Near-field cathodoluminescence (NFCL)-Based on near-field scanning optical microscopy (NSOM), this SPM is designed for surface-sensitive cathodoluminescence. The luminescence is excited by the electron beam and detected through the optical fiber positioned in the near field.

\section{DUAL-BEAM FOCUSED-ION-BEAM (FIB) WORKSTATION}

This dual-beam instrument consists of a focused-ion-beam (FIB) column and a scanning electron microscope (SEM) column on the same platform. Uses include ion milling, metal deposition, ion

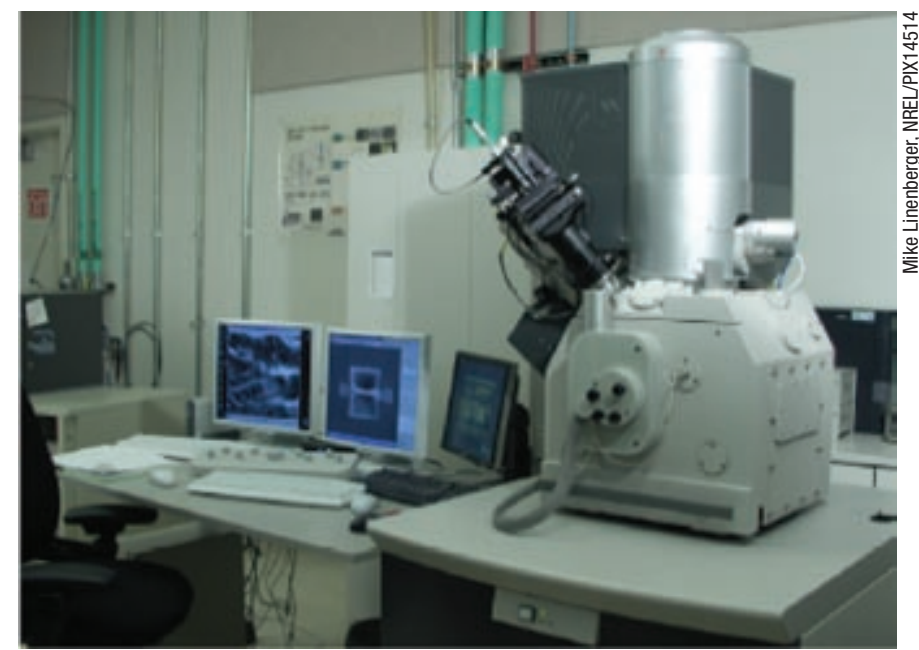

NREL's dual-beam focused-ion-beam workstation for fabricating microscopy samples and nanostructures.

imaging, and electron imaging on the micrometer and nanometer scale of advanced photovoltaic materials and devices. Supporting other analytical tools such as TEM, the dual-beam FIB performs precise, site-specific sample preparation for both TEM and SEM. Acquiring chemical spectra and elemental maps is another feature of this system with energy-dispersive spectroscopy (EDS). 3D chemical reconstructions can be obtained by combining controlled ion milling with chemical mapping. The FIB is equipped with a gas injection system (GIS) Pt metal deposition capability that can be used with either ion-beam-assisted or electron-beam-assisted chemical vapor deposition. Using a digital patterning generator also allows for complete FIB milling or deposition of complex structures with software-supplied parameters and/or by direct input of bitmap files.

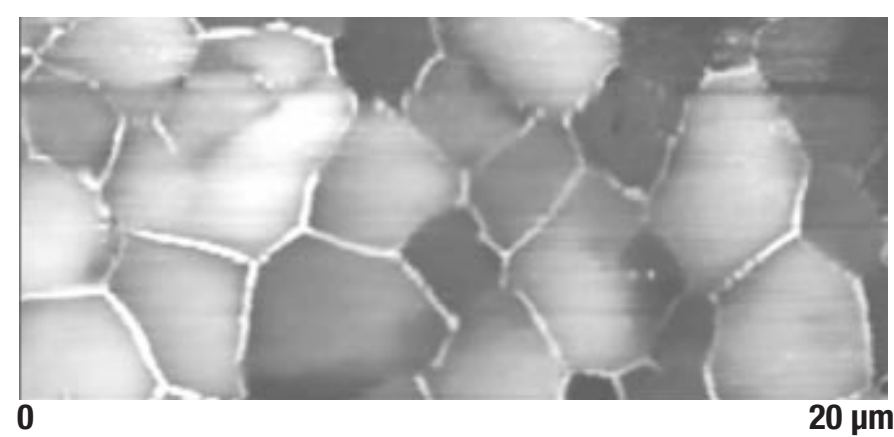

Conductive atomic force microscopy image of CdTe sample after bromine/methanol etching shows enhanced electric current at grain boundaries.
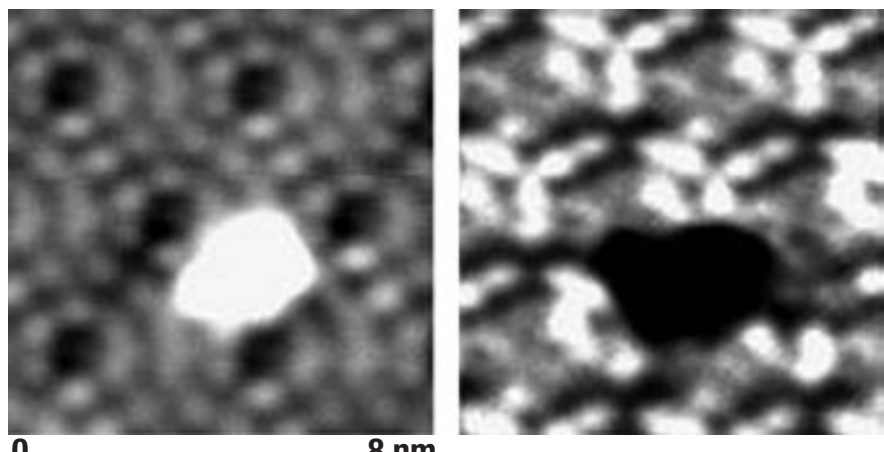

$8 \mathrm{~nm}$

Scanning tunneling microscopy image (left) shows morphology of a Si cluster on Si surface, and spectroscopic imaging (right) shows spatial mapping of density of states at 1 eV above Fermi level. 


\section{MAJOR INSTRUMENTATION FOR SCANNING PROBE MICROSCOPY}

\begin{tabular}{|c|c|c|c|c|c|}
\hline System & Analytical Technique & Typical Applications & $\begin{array}{l}\text { Lateral } \\
\text { Resolution }(\AA)\end{array}$ & \begin{tabular}{|l|} 
Vertical \\
Resolution $(\AA)$
\end{tabular} & Vacuum \\
\hline Veeco AutoProbe CP & $\begin{array}{l}\text { AFM, STM, SKPM, } \\
\text { SCM }\end{array}$ & $\begin{array}{l}\text { Nanoscale characterization of sample } \\
\text { morphology and electrical properties }\end{array}$ & $<1$ & $<0.1$ & No \\
\hline $\begin{array}{l}\text { Veeco Dimension } \\
3100 \text { - Nanoscope } \\
\text { Illa }\end{array}$ & $\begin{array}{l}\text { AFM, STM, SKPM, } \\
\text { SCM, C-AFM }\end{array}$ & $\begin{array}{l}\text { Nanoscale characterization of sample } \\
\text { morphology and electrical properties }\end{array}$ & $<1$ & $<0.1$ & No \\
\hline $\begin{array}{l}\text { Veeco Dimension } \\
3100 \text { - Nanoscope V }\end{array}$ & $\begin{array}{l}\text { AFM, STM, SKPM, } \\
\text { SCM, C-AFM }\end{array}$ & $\begin{array}{l}\text { Nanoscale characterization of sample } \\
\text { morphology and electrical properties, } \\
\text { including close-loop tip positioning }\end{array}$ & $<1$ & $<0.1$ & No \\
\hline $\begin{array}{l}\text { Omicron } \\
\text { VT-STM/AFM }\end{array}$ & $\begin{array}{l}\text { AFM, STM, SKPM, } \\
\text { C-AFM }\end{array}$ & $\begin{array}{l}\text { Nanoscale and atomic characterization } \\
\text { of sample morphology and } \\
\text { electrical/electronic properties }\end{array}$ & $<1$ & $<0.1$ & $10^{-11}$ torr range \\
\hline
\end{tabular}

\section{SCANNING PROBE}

MICROSCOPY (SPM)

A group of scanning probe microscopy (SPM) techniques uses very sharp tips that scan extremely close (several $\mathrm{nm})$ to or in contact with the material being analyzed. The signal used to map and analyze the surface may be generated in a number of ways: attractive/repulsive forces, electric current, or even friction force. The techniques we use include scanning tunneling microscopy (STM) and atomic force microscopy (AFM), with variants such as scanning Kelvin probe microscopy (SKPM), conductive AFM (C-AFM), scanning capacitance microscopy (SCM), and scanning tunneling spectroscopy (STS).

Features

- Spatial resolution to atomic scale.

- Digital data acquisition, allowing real 3D imaging and measurements such as roughness and surface linescan.
- Nondestructive.

- Can be performed in air or in ultra-high vacuum.

- Field of view is from atoms to about $100 \mu \mathrm{m}$ (vertical limit of $7 \mu \mathrm{m}$ ).

- AFM uses the force between the tip and sample surface; STM uses the tunneling current between the tip and sample surface.

\section{Applications}

- Surface imaging. Scans the surface of materials to produce topographic images with up-to-atomic resolution.

- Electrical and electronic properties. Can obtain these properties of samples with excellent spatial resolution. Analysis of properties that include surface potential (SKPM), type and concentration of charge carriers (SCM), electric conductivity (C-AFM), and local density of states (STS).

- Various materials. Can be used to analyze most types of materials, from conductors to insulators. Can provide information on the properties of semiconductor devices-e.g., potential profile along $p-n$ junctions by analyzing their cross sections.

\section{NPE}

National Renewable Energy Laboratory 1617 Cole Blvd., Golden, C0 80401

NREL is a national laboratory of the U.S. Department of Energy, Energy Efficiency and Renewable Energy, operated by Midwest Research Institute $\bullet$ Battelle
Measurements and Characterization is within the National Center for Photovoltaics at NREL Web site: www.nrel.gov/pv/measurements Phone: (303) 384-6675 • Fax: (303) 384-6604 Contract No. DE-AC36-99-G010337 NREL/BR-520-40120 • June 2006
NOTICE-This report was prepared as an account of work sponsored by an agency of the United States government. Neither the United States government nor any agency thereof, nor any of their employees, makes any warranty, express or implied, or assumes any legal liability or responsibility for the accuracy, completeness, or usefulness of any information, apparatus, product, or proces disclosed, or represents that its use would not infringe privately owned rights. Reference herein to any specific commercial product, process, or service by trade name, trademark, manufacturer, or otherwise does not necessarily constitute or imply its authors expressed herein do not necessarily state or reflect those of the United States government or any agency thereof.

Printed on paper containing at least $50 \%$ wastepaper, including $20 \%$ postconsumer waste 